\title{
Sob as sombras do discurso colonial: subalternidade e configurações de gênero em uma lavanderia do interior de Minas Gerais
}

\author{
Under the shadows of colonial discourse: subalternity and gender setups in a launderette in \\ the countryside of Minas Gerais
}

\author{
Alexandre Reis Rosa ${ }^{1}$ \\ Cintia Rodrigues de Oliveira Medeiros ${ }^{2}$ \\ Valdir Machado Valadão Júnior ${ }^{3}$
}

\begin{abstract}
Resumo
Neste artigo, abordamos a questão de gênero tendo por base o feminismo pós-colonial. Nosso objetivo é analisar as configurações de gênero em uma lavanderia comunitária localizada no interior de Minas Gerais, na qual trabalham apenas mulheres sob a liderança de uma mulher negra e pobre. Recorremos ao pensamento pós-colonial, especificamente às reflexões sobre a subalternidade feminina em Mohanty (1984), Spivak (1988) e Suleri (1992). O esforço dessas autoras para compreender a dinâmica de gênero traz à tona questões pouco observadas pelas teorias tradicionais, principalmente as de caráter dual que abordam gênero como uma simples relação entre sexos. Por sua vez, o pensamento pós-colonial apoia-se nos conceitos de subalternidade, não lugar e outros para refletir sobre os sujeitos pós-coloniais que falam por meio de representantes cuja legitimidade se dá pelo lugar, e não pela fala em si. Como método, utilizamos a técnica shadowing para acompanhar o cotidiano de trabalho da gestora dessa lavanderia e identificar a dinâmica de gênero que emerge das suas interações cotidianas. Como resultados, apresentamos as configurações das relações de gêneros, as quais consistem em nossas interpretações, que são, portanto, subjetivas, das práticas discursivas que emergiram durante o cotidiano de Cida, a gestora shadowed na lavanderia.
\end{abstract}

Palavras-chave: Subalternidade. Feminismo pós-colonial. Shadowing.

\begin{abstract}
In this paper, we approach the gender issue from a postcolonial feminist perspective. Our aim is to analyze gender setups in a launderette located in the countryside of Minas Gerais, where only women work under the leadership of a poor black woman. We relied on the postcolonial thought, specifically on reflections about the inferiority of women in Mohanty (1984), Spivak (1988), and Suleri (1992). The efforts of these authors to understand the gender dynamics brings up issues which are rarely observed by traditional theories, especially those with a dual nature addressing gender as a simple relationship between the sexes. In turn, the postcolonial thought leans on the concept of subordination, noplace, and other ones to reflect upon the postcolonial subjects who speak through representatives whose legitimacy is

${ }^{1}$ Doutor em Administração Pública e Governo pela Fundação Getúlio Vargas/EAESP; Professor associado da FUCAPE Business School. Endereço: Av. Fernando Ferrari, 1358, Sala 16, Boa Vista, CEP 29075-505, Vitória - ES, Brasil. E-mail: alexandre@fucape.br

2 Doutorando em Administração de Empresas pela FGV/EAESP; Professora da Faculdade de Gestão e Negócios da Universidade Federal de Uberlândia. Endereço: Av. João Naves de Ávila, 2121, Campus Santa Mônica, Bloco F - sala 1F225, CEP 38408-144, Uberlândia - MG, Brasil. E-mail: cintia@fagen.ufu.br

${ }^{3}$ Doutor em Engenharia da Produção pela Universidade Federal de Santa Catarina; Professor do Programa de Pós-graduação em Administração e da Faculdade de Gestão e Negócios da Universidade Federal de Uberlândia. Endereço: Av. João Naves de Ávila, 2121, Campus Santa Mônica, Bloco F - sala 1F225, CEP 38408-144, Uberlândia - MG, Brasil. E-mail: valdirir@ufu.br
\end{abstract}


related to the place, instead of their speech itself. As a method, we use the shadowing technique to observe the daily work of the launderette's manager and to identify the gender dynamics emerging from her everyday interactions. As a result, we present the configurations of gender relations, which consist of our interpretations, which are, thus, subjective ones, of the discursive practices that emerged during the daily work of Cida, the manager who was shadowed in the launderette.

Keywords: Subalternity. Postcolonial feminist. Shadowing.

\title{
Introdução
}

\author{
E se somos Severinos iguais em tudo na vida, \\ morremos de morte igual, mesma morte Severina: \\ que é a morte de que se morre de velhice antes dos trinta \\ de emboscada antes dos vinte, de fome um pouco por dia \\ (de fraqueza e de doença é que a morte Severina \\ ataca em qualquer idade, e até gente não nascida).
}

João Cabral de Melo Neto

No fragmento do poema em epígrafe, o protagonista Severino encarna os retirantes do sertão, "iguais em tudo na vida", condenados a viver uma "vida Severina" e a morrer uma "morte Severina" - uma situação que une todos os nordestinos que vivem no sertão árido, submetidos ao domínio, à violência e à exploração de coronéis. Esses severinos, sem meios de produzir para sua subsistência, e sem poder se fazer ouvir, emigram de suas terras ou moradias para as cidades. Porém, a vida Severina é cheia de privações, tanto no campo como nas cidades. Não é por acaso que o autor do poema representa todo um povo na figura de Severino, que, ao mesmo tempo, é ninguém e todo mundo. Severino sabe-se sem identidade e se sabe uma gente que não tem direitos. Severinos são homens e mulheres colonizados dentro de sua própria terra, configurando um perfil de gênero que demanda uma representação, pois se inscrevem no âmbito daqueles sujeitos que precisam ser representados para se fazerem ouvir.

"Vida" e "morte" severinas podem ser vistas como um retrato do processo de dominação no qual o colonizador consolida sua posição por meio do discurso social e constitui, dessa forma, o sujeito subalterno. A situação pós-colonial é reconhecida pela posição de subalternidade dos sujeitos que não têm lugar nas narrativas oficiais. É nesse sentido que o pensamento colonial apoia-se nos conceitos de subalternidade, não lugar, e outros, para refletir sobre os sujeitos pós-coloniais que falam por meio de representantes cuja legitimidade dá-se pelo lugar, e não pela fala em si. Contudo não se trata de um sujeito homogêneo; existem subalternidades dentro dessa categoria, e nesta há múltiplas formas de opressão geradas pelo colonialismo. Essas formas de opressão incluem o nordestino descrito na epígrafe, os negros, indígenas e mulheres - todos historicamente representados no discurso oficial como sujeitos subalternos que vivem à sombra de outros sujeitos que os representam.

Entre estas subalternidades, destacamos as mulheres que, segundo Spivak (1988), sofrem o que ela denomina de dupla colonização, pelo fato de serem mulheres nascidas em uma (ex)colônia. Isso nos remete a uma dupla reflexão sobre as formas de opressão sofridas pelas mulheres: na relação com o patriarcalismo, todas as mulheres são afetadas; e com o colonialismo, apenas as mulheres do chamado "Terceiro Mundo". Esta última reflexão problematiza o fato de que ser mulher, branca, heterossexual e nascida no chamado "Primeiro Mundo" é bem diferente de ser, por exemplo, mulher, negra, homossexual, nascida em um país africano ou latino-americano. São essas diferenças - ignoradas pelo feminismo ocidental - que o feminismo pós-colonial tem trazido para o debate (MOHANTY, 1984). 
No âmbito dos Estudos Organizacionais, os estudos de gênero acabam reproduzindo o mesmo silêncio diante dessas diferenças. Mesmo dispondo de um amplo conjunto de abordagens de gênero (CALÁS e SMIRCICH, 1996), a maior parte dos estudos no campo ainda se orienta pela perspectiva do feminismo ocidental, pela qual as mulheres são vistas de forma homogênea, não obstante as diferenças apontadas pelo feminismo póscolonial (CALÁS, 2007).

Nesse sentido, a análise da produção científica de estudos de gênero em Administração, realizada por Cappelle et al. (2006), evidencia que essa tendência se repete nas análises de gênero nos estudos organizacionais brasileiros. Essa pesquisa levantou os artigos publicados em anais do EnANPAD e em periódicos científicos Qualis A, nos anos de 1995 a 2004, tendo identificado um predomínio $(51,11 \%)$ de estudos de gênero em perspectiva liberal, na qual se adota uma visão dual, e homens e mulheres são separados e dispostos em uma relação de dominação (CAPELLE et al., 2006). Nessa perspectiva, a mulher, o polo dominado, é representada de forma homogênea, muitas vezes como espelho da mulher do "Primeiro Mundo", com curso superior e ocupando funções executivas, assim como problematiza o feminismo póscolonial.

Nessa análise, Cappelle et al. (2006) identificaram a ausência de estudos em uma abordagem póscolonial/terceiro-mundista, que aparece apenas de forma híbrida, com outras abordagens teóricas, o que pode ser explicado pela fragilidade das fronteiras entre elas. Ainda nessa análise, os autores identificaram o predomínio da dualidade do sexo na concepção de gênero, além de seu caráter universal e generalizante, não havendo, por parte dos autores pesquisados, tentativa de relacionar o gênero a outras categorias, como "[...] especificidades culturais, sociais, locais e organizacionais de cada caso [...]" (CAPPELLE et al., 2006, p. 9). A ausência de estudos feministas pós-coloniais nos principais periódicos nacionais, levantada por Cappelle et al. (2006), reforça a contribuição deste estudo no sentido de estimular trabalhos que reconheçam as diferenças para além do sexo, de forma a incluir outras categorias, desconstruindo a representação de um sujeito universal.

Considerando o contexto apresentado, nosso objetivo, neste artigo, é abordar a questão de gênero com base no feminismo pós-colonial, por meio de análise das configurações de gênero em uma lavanderia comunitária localizada no interior do Estado de Minas Gerais, onde trabalham apenas mulheres sob a liderança de uma mulher negra e pobre. Como procedimentos metodológicos, utilizamos a técnica shadowing para acompanhar o cotidiano de trabalho da gestora da lavanderia e identificar a dinâmica de gênero que emerge nas suas interações cotidianas. Quanto à teoria, recorremos ao pensamento pós-colonial, especificamente às reflexões sobre a subalternidade feminina em Mohanty (1984), Spivak (1988) e Suleri (1992). Essas autoras nos ajudam a compreender como a dinâmica de gênero, no espaço analisado, traz à tona questões pouco observadas pelas teorias tradicionais de gênero, principalmente aquelas de caráter dual que abordam a questão de gênero como uma simples relação entre sexos.

Organizamos o artigo da seguinte forma: na primeira seção, discutimos a concepção de gênero como categoria socialmente construída e reproduzida nas diversas interações entre outras categorias como raça, classe, religião, etnia e geração. Em seguida, mostramos como o feminismo pós-colonial encara essas questões. Na terceira parte, descrevemos os procedimentos metodológicos utilizados no estudo e, na quarta parte, apresentamos as configurações de gênero identificadas e discutimos os resultados encontrados à luz da perspectiva pós-colonial. Por fim, encerramos com as considerações finais apontando possíveis desdobramentos para o estudo de gênero no campo dos Estudos Organizacionais.

\section{Para além dos Dualismos Ocidentais de Sexo e Gênero}

Em sua gênese, o conceito de gênero era sinônimo de "mulher", ou seja, os estudos de gênero nada mais eram do que estudos sobre a mulher (SCOTT, 1988). O esforço da militância feminista dirigia-se para trazer 
à tona a dimensão feminina dos processos sociais, sobretudo, por meio de uma releitura da história social, que, de alguma forma, "esqueceu" o relevante papel das mulheres na evolução social. Nesse campo, destacam-se os trabalhos de Michele Perrot $(1988,1990)$, que se empenhou em escrever uma "história das mulheres" articulando o conceito de gênero aos diversos episódios históricos que marcaram as mudanças políticas, econômicas e sociais da humanidade. Dessa forma, outras áreas de estudos também fixaram o olhar na mulher, tratando-a como agente privilegiado, subvertendo a ordem masculina presente nos estudos até então elaborados.

No entanto, ao fixar o olhar apenas na "mulher" ou na "condição feminina", além de anular a influência do outro (homem) na construção da subjetividade feminina, também "[...] deixa a impressão de que os homens existem em algum lugar além do social, como se - mais uma vez - o masculino constituísse um parâmetro extra-histórico e englobante" (FONSECA, 1998, p. 17). Assim, diferentemente das primeiras análises, emergem os estudos que passam a olhar a categoria "gênero" como resultado de uma relação entre mulheres e homens, ou melhor, entre feminilidades e masculinidades, observando-a, sobretudo, como uma relação de poder muito mais ampla do que a simples dualidade homem-mulher.

Em uma revisão histórica dos estudos de gênero, Costa (1994) identifica que o conceito transitou por diversas vertentes, as quais the deram diferentes ênfases de pesquisa. A primeira aborda o gênero como variável binária, pois enfoca a diferença sexual (homem e mulher) como determinante da forma pela qual os gêneros assumem linguagens diferentes. Essa vertente centra-se em uma lógica estática e dualista, enraizada em pressuposições biológicas que impedem a compreensão do contexto sócio-histórico-cultural no qual os indivíduos estão inseridos.

A segunda vertente trata o gênero como papéis sexuais dicotomizados, enfatizando dualismos por meio de uma abordagem de papéis sociais atribuídos a homens e mulheres. Essa vertente, apesar de abandonar o fator biológico presente nas leituras binárias, continua a considerar a dicotomia dos papéis sociais de homens e mulheres como determinantes da diferença, sem procurar entender como esses são definidos e quem os determina.

A terceira vertente aborda gênero como uma variável psicológica, assumindo a diferença entre homem e mulher nos termos de um grau expresso por uma escala na qual o mais masculino ficaria em um extremo e o mais feminino, no outro, e, entre ambos, se localizariam todos os indivíduos. Porém, nessa escala, não se demonstra a mensuração, tampouco o que significa ser mais masculino ou mais feminino, perpetuando as noções tradicionais de masculinidade e feminilidade que ela mesma se propunha dissolver.

Outra vertente assume gênero como uma tradução de sistemas culturais, sendo a trajetória de vida dos indivíduos a responsável pelas diferenças entre homens e mulheres, considerando-se, nessa trajetória, a presença de uma socialização engendrada. Nessa perspectiva, meninos e meninas são educados para agirem e se comunicarem de forma distinta, criando subculturas ou mundos diferentes, que, muitas vezes, podem obnubilar a questão, impedindo que se percebam mecanismos de dominação de um mundo sobre o outro.

Uma última vertente assume gênero como fenômeno relacional. Nesta, abandona-se a visão binária e a divisão de papéis, permitindo-se uma concepção dinâmica de masculinidade e feminilidade conforme as relações entre os gêneros e a interação dialética entre a prática social e a estrutura social. Com isso, assumese a relação do indivíduo com seu contexto social e seus vários fatores que influenciam a formação dos sujeitos mediante escolhas individuais feitas por homens e mulheres.

No âmbito dos Estudos Organizacionais, Calás e Smircich (1996) apresentam, também, diversas concepções da categoria gênero - descritas a seguir -, de acordo com os tipos de abordagens elaboradas pelas teorias feministas. Liberal: o gênero é socializado em seres humanos sexuados pelo comportamento adequado a cada sexo. Radical: o gênero é uma construção social que assegura a subordinação das mulheres aos homens. Psicanalítica: o gênero estrutura um sistema social de dominação masculina que influencia o 
desenvolvimento psicossexual. Marxista: é parte de relações históricas de classe que constituem sistemas de opressão sob o regime capitalista. Socialista: é constituído processual e socialmente por meio de diversas intersecções de sexo, raça, ideologia e experiências de opressão sob o patriarcado e o capitalismo (que são distintos). Pós-estruturalista: sexo e gênero são práticas discursivas que constituem subjetividades específicas por meio do poder e resistência na materialidade dos corpos humanos. Pós-colonialista: considera a constituição de subjetividades complexas que vão além dos conceitos ocidentais de sexo e gênero, enfocando aspectos de gênero articulados com classe, raça, etc., presentes nos processos de globalização.

Em sobreposição às classificações de Costa (1994) e Calás e Smircich (1996), podemos dizer que as leituras e concepções que mais superam os dualismos e abordam as múltiplas formas de opressão embutidas na categoria gênero são aquelas que assumem gênero como fenômeno relacional. Em seguida, a abordagem de gênero como tradução de sistemas culturais e a abordagem pós-colonialista, com alguns elementos da abordagem pós-estruturalista, em particular, no que tange às práticas discursivas que constituem as subjetividades. Com essas combinações, temos uma abordagem capaz de fornecer alternativas teóricas para analisar a questão de gênero nas organizações.

\section{Feminismo Pós-colonial e a Questão da Subalternidade}

A teoria pós-colonial surge como exigência de um espaço no qual a voz dos sujeitos periféricos pode-se fazer ouvir. Essa exigência por um lugar para a fala não se restringe apenas às colônias ou ex-colônias, mas, refere-se, também, a todas as populações que vivem em uma situação de insuficiência representativa na qual os sujeitos não são capazes de expor seu conhecimento sobre os fatos. Esses sujeitos estão inseridos, em geral, em populações marginalizadas, como grupos étnicos e imigrantes em países desenvolvidos, colonizados, indígenas e outros grupos de oprimidos, como as mulheres (PRASAD, 2003).

Os estudos pós-coloniais guardam muitas semelhanças com os estudos feministas. Segundo Ashcroft (1989), ambos estão essencialmente preocupados com as teorias de marginalização e a construção do sujeito subalterno, seja pela diferença colonial ou de gênero. Essa aproximação ocorre em virtude da preocupação com a "voz silenciada" dos subalternos resultante da maneira como as mulheres ou os sujeitos colonizados foram levados a constituir sua individualidade nos termos do opressor. Além disso, ambos questionam o conceito de universalização e rejeitam as estruturas binárias do patriarcado e do colonialismo, buscando estratégias de resistência a essas formas de dominação.

No entanto, o pensamento pós-colonial tem sido um campo de estudos que problematiza o feminismo ocidental com base em uma crítica ao conceito universal de "mulher" fundado em uma perspectiva eurocêntrica. Como ressalta Chanda (2005), o pensamento pós-colonial questiona o feminismo estritamente definido, que isola gênero de todas as outras formas de opressão, assumindo o pressuposto de que a erradicação da discriminação de gênero é o caminho para acabar com a opressão de todas as mulheres em face do patriarcado global, que obscurece as diferenças reais entre mulheres, negando a possibilidade de heterogeneidade.

As feministas pós-coloniais têm resistido também à tendência de as feministas ocidentais caracterizarem todas as mulheres fora do Ocidente como uma categoria essencializada, homogênea e unificada. A principal crítica nesse sentido foi feita por Mohanty (1984), que analisou uma série de publicações acadêmicas sobre as mulheres do "Terceiro Mundo", frutos de pesquisas realizadas por estudiosos europeus que utilizaram suas próprias culturas como norma para representar as mulheres nativas dos países periféricos como um tipo "Outro". Esses estudos definem essas mulheres em termos de pobreza, ignorância, vitimização, vida doméstica e orientadas para a família, como se todas as mulheres do "Terceiro Mundo" precisassem de uma representação pelo fato de não terem uma voz própria contra o patriarcalismo. Desde então, outras feministas 
pós-colonialistas problematizam a autenticidade das narrativas elaboradas pelo feminismo ocidental que colocam uma parcela significativa das mulheres do mundo como "o outro", colocando-as em um lugar de enunciação subalterno (SULERI, 1992), no qual são impedidas de falar (SPIVAK, 1988).

Essa condição de subalterno coloca-se como a principal diferença entre os povos do Ocidente e do "resto" do mundo (HALL, 1996). No caso das mulheres, essa condição é o mecanismo que as encerra em um tipo de "dupla colonização" pelo fato de ser mulher em uma nação colonizada. Ou seja, além dos efeitos gerados em uma estrutura patriarcal, elas estão, também, sob os efeitos do colonialismo. Assim, historicamente, a condição do subalterno é a condição do silêncio, pois sua legitimidade tem sido dada por outra pessoa que assume seu lugar no espaço público, representando-o. Com efeito, o subalterno se torna dependente de mediadores para que seja considerado ator legítimo de reivindicação - leia-se o feminismo ocidental. Contudo, ao aceitar essa condição de representado, o subalterno torna-se objeto na mão do representante e, com isso, não se constitui plenamente (SPIVAK, 1988). Daí a necessidade de o subalterno ocupar a brecha dos discursos, apropriando-se do modo como serão representados em esferas deliberativas, cuja pauta será definida mediante suas próprias reivindicações. A noção de subalternidade é uma tentativa de ampliar a noção de opressão, marcando, assim, a insatisfação com o conceito de gênero que não leva em conta questões como classe, raça e sexualidade.

$\mathrm{Na}$ experiência brasileira, o patriarcalismo está intimamente relacionado ao período colonial da nossa formação, quando predominou um modelo de organização familista, no qual a "família" era a expressão máxima da organização social da época. A esfera privada, dominada pelo patriarca, tinha um papel determinante nos rumos da economia e da administração colonial e, de certa forma, predominou, também, no período imperial e na primeira república (ESTEVES, 1998). Até que o modelo familista colonial começasse a ruir, com o fim da escravidão em 1888, "[...] a mulher do senhor se limitava à sua vida familiar, à procriação dos filhos e aos contatos com os escravos e amas, aos parentes e, por vezes, aos padres" (D’ÁVILA NETO, 1980, p. 36). Nessa mesma esfera privada colonial, como relata Freyre (1988), estava, também, sob o domínio do patriarca, outra categoria de mulher: a negra, escrava, analfabeta e pobre.

Nos anos seguintes, as mulheres brancas, ricas e alfabetizadas, filhas dos senhores de engenho, iniciam um longo processo de emancipação feminina na medida em que "[...] deixaram de restringir suas aspirações ao casamento e aos filhos. Desafiaram a dicotomia entre público e privado, conquistaram direitos como cidadãs, constituíram-se como indivíduos. $\mathrm{O}$ individualismo patriarcal foi abalado e a igualdade entre homens e mulheres colocou-se como possibilidade social" (VAITSMAN, 2001, p. 16). Todavia aquela outra categoria de mulher, negra, analfabeta e pobre, ficou à margem desse processo, limitando-se a conviver com as mesmas privações da vida colonial, vendendo seu trabalho doméstico para conseguir seu sustento (SANTOS, 2001). Mesmo nos dias atuais, a mulher subalterna ainda amarga os piores níveis de escolaridade, com rendimentos menores em comparação com as mulheres brancas, ainda que exercendo as mesmas atividades, e, ainda, com menores possibilidades de ascensão social em virtude do estigma racial (CARNEIRO, 2003).

Por conseguinte, quando as pesquisas na área de Estudos Organizacionais no Brasil se dedicam a identificar, por exemplo, os mecanismos para romper o "teto de vidro" de organizações (STEIL, 1997), o estilo de gestão de executivas em empresas familiares (GRZYBOVSKI, BOSCARIN e MIGOTT, 2002), a representação das mulheres em revistas de negócios (MELO et al., 2004), o assédio moral que as mulheres sofrem nas organizações (CORRÊA e CARRIÉRI, 2007), ou a inserção das mulheres no agronegócio (PEREIRA, MACHADO e VILAS BOAS, 2008), apenas buscam analisar aspectos importantes da presença feminina nas organizações, porém, não consideram as diferenças como etnia, origem e orientação sexual que, principalmente, o feminismo pós-colonial tem debatido.

No limite, essas mulheres podem ser vistas como um retrato tropical da famosa "Ellen Randal", mulher universal tomada como exemplo por Calás e Smircich (1996) para ilustrar as múltiplas possibilidades de pesquisa sobre gênero nas organizações. Quando se depara com as demandas do sujeito subalterno sob seu comando, Randal não sabe o que fazer; recorre, então, à sua amiga antropóloga pós-colonial. 


\section{Shadowing: o Campo de Estudos em Movimento}

Para investigar a configuração de um possível perfil das relações de gênero, com o objetivo de revelar como as construções de gênero definem as relações de poder entre as mulheres permissionárias em uma lavanderia comunitária, observamos, por meio da técnica shadowing, o trabalho de uma gerente da lavanderia, também permissionária. Segundo Mcdonald (2005), essa técnica de pesquisa tem sido mais comum em pesquisas sobre educação, treinamento clínico de estudantes de medicina e em estudos para compreender os papéis de outras profissões. No campo dos Estudos Organizacionais, a técnica tem sido aplicada no estudo do trabalho gerencial, como o de Mintzberg (1973). A shadowing se diferencia da observação estruturada e da observação participante pelo fato de que o acompanhamento individual torna o pesquisador mais hábil a responder o porquê das questões de pesquisa (QUINLAN, 2008).

Valendo-se da premissa de que a técnica é adequada para coletar dados sobre os papéis desempenhados por profissionais e sobre o trabalho em organizações (CZARNIAWSKA, 2007), optamos por usá-la para investigar o perfil das relações de gênero produzidas no cotidiano do trabalho de uma mulher cuja imagem é diferente daquela ocidentalizada. Essa opção é justificada pela riqueza de informações obtidas durante o acompanhamento do cotidiano de um indivíduo, pois, é nesse espaço temporal e material que se produzem as relações sociais. Segundo Mcdonald (2005, p. 458), essa técnica adiciona uma nova perspectiva na pesquisa organizacional, visto que permite capturar o movimento da "[...] natureza provisória, fragmentada, variada, verbal e ininterrupta da vida organizacional", o que não é possível por meio de entrevistas e da observação participante.

A lavanderia comunitária foi criada com o objetivo de potencializar condições de trabalho para mulheres com filhos pequenos. Na condição de permissionária, as mulheres têm flexibilidade no horário de trabalho e podem levar seus filhos pequenos para que permaneçam no local enquanto trabalham. Essa condição, aliada à natureza do trabalho comunitário, constitui um espaço em que as permissionárias não estão sujeitas à subordinação de um "patrão" ou proprietário, pois cada uma delas tem responsabilidades sobre o seu trabalho individual, bem como sobre o trabalho coletivo na lavanderia. Assim, o campo selecionado para esta pesquisa caracteriza-se como um espaço em que a ausência dessa subordinação pressupõe, também, um modelo autogestionário que reconfigura as relações de poder nesse espaço.

Para a utilização dessa técnica, orientamo-nos pela revisão de Mcdonald (2005), segundo a qual o shadowing consiste em uma técnica de pesquisa em que o pesquisador acompanha de perto um membro de uma organização em um determinado período de tempo que pode ser compreendido "[...] a partir de um único dia ou até o deslocamento de um mês inteiro" (MCDONALD, 2005, p. 456). Nesta pesquisa, optamos por aplicar a técnica durante cinco dias, período que compreende a semana de trabalho da lavanderia, qual seja, de segunda a sexta-feira.

McDonald (2005) explica que a técnica pode focalizar um papel ou cargo específico ou um número variado de papéis e cargos dentro de uma mesma organização. Por se focalizar no movimento, a unidade de análise não é o indivíduo, mas, sim, a relação social (QUINLAN, 2008). Durante cinco dias, acompanhamos o trabalho da gerente permissionária e, com base nas observações realizadas, fizemos anotações sobre suas conversas com clientes, com colegas e com outras pessoas que estiveram no local. As anotações buscaram registrar, também, a linguagem gestual da permissionária shadowed e, ao final do período de shadowing, deparamo-nos com um corpus de pesquisa rico e detalhado sobre a rotina de trabalho dessa gerente.

A contribuição dessa técnica de pesquisa para o campo dos Estudos Organizacionais reside basicamente em dois pontos: (1) produz dados primários com riqueza de detalhes pelo acesso do pesquisador sobre aspectos organizacionais que, de outro modo, seria difícil obter (MCDONALD, 2005); e (2) permite investigar o que realmente as pessoas fazem no decorrer do seu dia, não o que os seus papéis prescrevem que devem fazer (PICKERING, 1992). 
Antes de iniciar a pesquisa de campo, consideramos as recomendações de Mcdonald (2005) sobre essa etapa: (1) inteiramo-nos sobre o nome das pessoas e sobre o campo de estudos; (2) utilizamos um caderno de campo para as anotações; (3) procuramos efetuar uma descrição com riqueza de detalhes; (4) fizemos anotações ao final do dia para preservar nossos pensamentos e impressões; e (5) decidimos registrar as conversas em gravadores de áudio para, posteriormente, transcrever e analisar os dados.

Para a análise do discurso, adotamos a metodologia foucaultiana, na qual se considera a função enunciativa articulada no campo social em que o discurso emerge. Foucault (1969) considera os discursos uma prática e não um conjunto de signos, frases ou elementos significantes. Para Foucault (1969), uma interrogação a ser feita é sobre o fato de o discurso analisado ter surgido naquele lugar e, não, em outro. Como o discurso constitui realidades, não é a fala e seus aspectos linguísticos que se analisam, mas, sim, as razões que levam as pessoas a fazerem determinadas afirmações. Neste artigo, consideraremos como discurso as conversas e diálogos que emergem nas relações sociais entre a permissionária shadowed e outros atores. A análise das práticas discursivas, como apregoa Foucault (1969), não objetivam as explicações universais ou generalizações e, sim, a descrição do modo pelo qual as histórias tornam-se verdadeiras.

\section{Explorando o campo de pesquisa}

As lavanderias comunitárias existem no Brasil desde os anos 1950, tendo sido criadas com o objetivo de promover a melhoria da qualidade e a organização da profissão de lavadeira, com a utilização de um modelo de autogestão e produtividade. Em Minas Gerais, na década de 1980, a Prefeitura Municipal de Uberlândia, por meio da Secretaria Municipal de Trabalho e Ação Social, implantou o programa denominado "Mãos à Obra", com o objetivo de incentivar a autogestão de negócios e a qualificação e requalificação de mão de obra. As lavanderias comunitárias também estavam incluídas no programa, mas, a partir de 1999, tornaramse independentes, e foram desligadas da assistência municipal. A alegação para o rompimento do vínculo é que elas já tinham atingido a maturidade administrativa (CALIXTO, 2001).

\section{Dentro do campo}

Nossa entrada no campo de pesquisa deu-se com uma visita inicial à lavanderia, previamente marcada em um contato telefônico, com o objetivo de conhecer a gerente e explicar detalhes da pesquisa. Nesta ocasião conhecemos Cida, que aceitou nossa proposta de pesquisa. Trata-se de uma mulher casada, negra, evangélica, mãe de três filhos homens, permissionária da lavanderia há cerca de 20 anos, professora de religião da Igreja de Jesus Cristo dos Santos dos Últimos Dias.

A partir de então, organizamos uma agenda de campo de acordo com o funcionamento da lavanderia, de 07h00min às $17 \mathrm{~h} 00 \mathrm{~min}$, com intervalo para o almoço de $11 \mathrm{~h} 00 \mathrm{~min}$ às $13 \mathrm{~h} 00 \mathrm{~min}$, de segunda a sexta-feira. Permanecemos em campo por 8 horas diárias, durante o mesmo horário de Cida, em um total de 40 horas semanais. Para o registro do acompanhamento, utilizamos um diário para anotações das conversas, de gestos e expressões, além dos acontecimentos presentes no cotidiano de trabalho de Cida.

No dia marcado, chegamos às 7h00min e encontramos Cida no seu posto de trabalho, acompanhada de outras duas permissionárias. O trabalho na lavanderia é feito por dois grupos de mulheres: passadeiras e lavadeiras, que trabalham em pares, ou seja, cada passadeira tem uma lavadeira como par. Sete mulheres compõem o primeiro grupo e trabalham no recinto que é, também, a entrada da lavanderia. Neste recinto, as passadeiras atendem os clientes, recebem e pesam a roupa e fazem a entrega. Descendo alguns poucos degraus, no piso inferior, localiza-se o recinto no qual as lavadeiras fazem o seu trabalho. Cida faz parte do primeiro grupo e, além disso, tem o cargo de gerente voluntariamente. Passados alguns minutos da nossa 
chegada, as outras permissionárias chegam e ocupam seus lugares. Quando todas já estavam lá, Cida dirigiuse a nós e disse: "- Venha, vou te apresentar para as outras". Iniciamos a "ronda" e Cida explicava: "Aqui, cada um tem seu material para trabalhar". A partir de então, observamos a emergência das configurações de gênero descritas a seguir.

\section{Configurações das relações de gênero}

Nesta seção, apresentamos as configurações das relações de gênero, as quais consistem em nossas interpretações e, portanto, subjetivas, das práticas discursivas que emergiram durante o cotidiano de Cida na lavanderia. As questões principais discutidas na teoria pós-colonial serviram-nos de orientação para evidenciar três configurações das relações de gênero: (1) consentimento - reforça o discurso colonial; (2) silêncio e submissão - cala-se diante do discurso colonial (3) resistência - nega o discurso colonial. Ầ luz das questões centrais dos teóricos pós-coloniais, identificamos nas conversas de Cida com outros atores que os sujeitos ora se apresentam dentro de uma configuração, ora em outra. Em face dessa constatação, agrupamos os textos de acordo com as configurações identificadas.

\section{Consentimento}

Nos trechos ora apresentados, observamos a situação na qual os textos reforçam o discurso colonial. Nas práticas discursivas, notamos como o discurso colonial se apresenta na fala de Cida e de seus interlocutores, revelando imagens e experiências sociais das mulheres e homens mais privilegiados do Primeiro Mundo.

No primeiro diálogo de Cida com Edilene, também permissionária, observamos como ambas concordam com as oposições binárias, nesse caso, homem-mulher, reveladoras do reducionismo ocidental no modo de organizar e dividir o mundo em apenas dois.

Cida - o mundo mudou muito para melhor. Se você observar, os homens trazem mais as roupas do que as mulheres.

Edilene - os homens conhecem mais as roupas dos filhos, da casa do que as mulheres.

Cida - as executivas não sabem o que acontece em casa.

Edilene - as mulheres não quer saber mais de trabalho de casa não. Fazer isso aqui? (aponta para o ferro de passar).

Continuando o diálogo com a permissionária Edilene, Cida reforça que na lavanderia o trabalho será destinado apenas a mulheres. Ao atribuir às mulheres o direito de trabalhar na lavanderia, Cida ratifica a ocupação de um espaço e, assim, reforça o estereótipo de que à mulher cabem os cuidados com os filhos, em um consentimento explícito ao patriarcalismo.

Cida - os maridos das clientes tratam a gente melhor. Prefiro trabalhar com homens. Aqui não abro para trabalhar homens. Foge do objetivo. O objetivo de ajudar as mulheres mães que precisam de flexibilidade.

Edilene - se abrir, tira o espaço das mulheres. 
Cida - o objetivo daqui é melhorar para as mães que precisam de flexibilidade, precisam trazer seus filhos, porque não têm lugar de deixar.

Em uma conversa entre as outras permissionárias sobre sonhos e desejos, Cida não se manifesta, apenas observa. $\mathrm{O}$ assunto é moda e a condição social das mulheres, demonstrando a polarização entre as mulheres de uma classe social elevada e as que pertencem a uma classe social inferior, desprovida de privilégios. Daí a noção de gênero, ampliada ao considerar outros elementos como classe social, revelar a existência de vários femininos e vários masculinos, apontando para a necessidade de reconhecer diferenças manifestadas dentro de outras diferenças.

Francisca (outra permissionária) - eu queria ter mesmo dinheiro pra me cuidar.

Edilene - mulheres que têm dinheiro se vestem bem. As pobres não têm privilégio nem pra ficar bonita.

Francisca - é o dinheiro que dá jeito.

Edilene - tudo que passa na TV depende dos olhos de quem vê. "Viver a Vida" é um tema muito bonito. Olha o caso da Luciana. Ela sofre, mas enfrenta. Tem que ser daquele jeito. Não é fácil. Mas também, pra vencer, só se for muito rico. Na novela mostrou muitas adaptações que foi feito na família pobre. Mas o exemplo na novela é de uma pessoa rica.

Edilene também revela conformidade com o fato de que o discurso dominante da mídia retrata a verdade, pois reforça a existência de "um" e do "outro"; nesse caso, ricos e pobres. Além disso, reforça a incapacidade do "outro" de reagir, apresentando uma imagem de que o vencedor é o colonizador, aquele que tem recursos. É assim que o oprimido, neste caso, a mulher, constitui sua individualidade, baseando-se na dominação do opressor, como sinaliza Ashcroft (1989) ao discutir o feminismo pós-colonial.

A universalização da mulher e do homem é recorrente nas conversas entre as permissionárias. Discutindo sobre os capítulos de uma novela televisiva, Cida expõe sua opinião sobre o comportamento de uma personagem, desqualificando-a por não ter uma atitude apropriada a uma mulher. Cida faz isso de modo generalizado, ratificando a construção de um sujeito universal, um conceito questionado no pensamento póscolonial.

Cida - o mundo gira no dinheiro. O interesse das pessoas é no dinheiro.

Cida - a menina que não sabe quem é o pai do filho na barriga. São problemas que acontecem na realidade. Ela é uma prostituta. Mulher interesseira. Não vende o corpo, mas vai atrás de homens para tirar proveito. Isso não é atitude de mulher. Não é uma prostituta, mas é uma vadia.

Angela - na novela passa o preconceito da mãe dos gêmeos. Ela não quer que um casa (sic) com uma prostituta e o outro com uma cadeirante.

O diálogo entre Cida e Edilene, conforme trecho a seguir, confirma a hierarquização presente na lavanderia, reforçando a existência de "um" e do "outro". Ser "lá de baixo" significa ter que cumprir as normas, seguir os padrões estabelecidos por quem já não mais lá está. 
Cida - sabe, eu não ganho nada para administrar. O trabalho é voluntário. Eu hoje passo, mas já fui lá de baixo. Hoje temos uma que lava e passa, até ela ter o número de clientes bastante.

Edilene - é, e já tem uma nova treinando, é eventual, mas quando a Angela tiver os clientes, ela (a novata) fica sendo a lavadeira dela.

(perguntamos a Cida sobre a entrada da novata)

Cida - eu passo pra ela nossos valores, diretrizes, ensino pra ela como é a produção e depois todo mundo ajuda. (pausa)

Cida - A pessoa que não se adequar aqui vai embora. Não pode ser do jeito que quer. Tem que fazer do jeito que tem que ser feito. Na casa da gente, sim, mas aqui não.

Edilene - teve uma aqui que queria cortar a etiqueta das roupas dos clientes. Ela dizia que tinha que cortar porque incomodava a pessoa.

Cida - falei que não podia, porque o povo gosta de ser outdoor. Então, a gente tem que trabalhar com paz na consciência.

Nos trechos anteriores ficam evidentes a necessidade de trilhar um caminho para alçar o estágio atual, e, ao mesmo tempo, a importância dos momentos de socialização para que as participantes adotem um mesmo comportamento frente ao cotidiano. Para estar no grupo, há que se conformar à verdade estabelecida.

Cida - aqui não é diferente de uma empresa. Aqui não é diferente de uma empresa. O maior problema aqui é o custo. O problema maior aqui são os custos. O ganho depende da produção. Se tem clientes, ganha. Se não tem, não ganha

Edilene - e não tem décimo terceiro. Se quiser ter, a gente tem que guardar todo mês.

Cida - O trabalho comunitário não tem encargo social. Somos registradas como autônomas. Só que não são todas que pagam. Se acontecer algo no futuro, não sei o que elas vão fazer.

O trabalho na lavanderia proporciona liberdade e flexibilidade, mas tem de funcionar como o de uma empresa. A redução de custos é importante. A participante não tem direito ao décimo terceiro salário e pode se prejudicar se não pagar o seguro social; contudo elas não têm alternativa para geração de trabalho e renda.

Um aspecto que pode ser observado no trabalho da lavanderia é a submissão do corpo. Em determinado momento, perguntamos a Cida o quão cansativo é permanecer em pé o tempo todo, sem nenhuma pausa.

Cida - já acostumei.

Edilene - é, a gente acostuma, nem sente. Eu dou um jeito de descansar fazendo caminhada no sábado e domingo.

Cida - descansar? A gente chega em casa e vai pras (sic) panelas, arruma a casa....

Edilene - e aqui é divertido. É cada coisa que a gente vê. Tem cliente que pega a roupa, põe na mala e vai direto pro aeroporto. Outros troca de roupa aqui mesmo ou carro, indo pro serviço. Outros deixa a roupa suja e veste a limpa. 
Cida - a gente vai pegando certa intimidade com o cliente.

O corpo se acostuma com o ritmo, consente as horas de trabalho árduo e ainda resigna-se à fadiga quando se sujeita à dupla jornada de trabalho que se completa no trabalho doméstico. Isso pode ser compensado por meio da intimidade com o cliente e o universo que ele proporciona: o aeroporto, a executiva, a agitação cotidiana, as marcas, e outros aspectos.

O consentimento com o discurso colonial, em que prevalece a imagem do homem branco, heterossexual e bem sucedido, é evidenciado na conversa de Cida com Edilene, logo após a retirada de um cliente.

Entra um cliente, elas olham uma pra outra e, depois que o cliente se retira:

Cida - esse cliente foi casado e agora é homo.

Edilene - tem cada um que é um desperdício

Cida - o desejo do homossexualismo deve ser banido. O homossexual confesso não é chamado pra trabalhar na igreja. Tem que respeitar quem é (homossexual). A igreja não tem preconceito. A pessoa só é banida.

Cida - o acerto da vida é com o Senhor. A destruição do Haiti? Aquilo foi mais uma sacudida do Senhor. Sodoma e Gomorra foram destruídas por causa do homossexualismo.

Cida - um rapaz lá na igreja, depois que assumiu, se afastou. Acho que ficou com vergonha.

Edilene - é uma pena, porque ele é um rapaz lindo, daria filhos lindos e bons, porque ele é uma boa pessoa.

Esses fragmentos são representativos da necessidade de estudos que considerem gênero como uma categoria na qual se inserem outras categorias marginalmente excluídas, como outras minorias.

\section{Resistência}

Aqui serão apresentados os fragmentos dos discursos que denotam a resistência, seja de modo explícito ou implícito, às ideias do discurso colonial. Observamos que essa configuração não está sempre presente nas conversas.

Cida - Aqui nós somos livres. Só tem uma coisa: é preciso ter liberdade com responsabilidade.

Edilene - nós temos horários livres pra trabalhar. Cada um almoça na hora que quer. Eu mesmo almoço na minha casa, moro aqui perto. Quem mora longe traz o almoço e esquenta aqui mesmo.

Cida - a minha vida aqui mudou muito pra melhor.

As conversas vão se desenvolvendo aos poucos, de forma fragmentada, como se elas se lembrassem de algo que é necessário falar. 
Cida - o nosso diferencial é lavar a roupa na mão.

Angela (permissionária) - outras lavanderias é tudo na máquina.

Cida - se lavar na máquina, despede as pessoas.

Durante uma negociação de preços com o fornecedor, Cida mostra-se segura e conhecedora do produto e dos preços relativos ao produto. Cida discute, utiliza uma calculadora para verificar a relação quantidade-valor e, com habilidade para negociar, consegue a redução do preço, além de condições mais prolongadas de pagamento e sem juros.

As conversas são esparsas. No rádio ouve-se um cidadão reclamando do atendimento médico de uma unidade de atendimento na cidade, o que estimula o seguinte diálogo:

Cida - acho injusto a diferença do salário do enfermeiro e do médico

Francisca - você viu a lei nova? Passou a vigorar esta semana. Vi na TV.

Edilene - outro dia eu fui no médico, ele perguntou o que eu tinha, falei que tava com uma dor no estômago e ele me receitou. Eu embolei a receita, joguei no lixo na frente dele, virei as costas e saí.

Cida - um médico perdeu o meu exame e pediu pra mim fazer outro. Eu virei pra ele e falei: "Você e eu sabemos que a consulta não é de graça. Enquanto você não faz o seu serviço, o povo paga". É falta de responsabilidade de todos.

No trecho a seguir, extraído de uma conversa entre as permissionárias Cida, Edilene e Francisca, observamos a resistência. O fato de não terem "patrão" e, ainda, a menção de que "o cliente não manda aqui", sinaliza para a não aceitação do discurso colonial, ou seja, é na lavanderia que as permissionárias encontram o lugar da fala, no qual não se deixa representar.

Cida - nós não temos patrão. Não tem ninguém pra mandar fazer nada. Numa empresa você enriquece o patrão e fica mais pobre. Se eu quiser sair agora para fazer alguma coisa, eu saio e volto.

Edilene - quando eu trabalhava na QG eu não tinha tempo pra mais nada. Agora eu descanso sábado, domingo. Trabalho aqui, faço o serviço de casa.

Cida - tem que ter responsabilidade. Se não tiver responsabilidade, a liberdade deixa de ter importância.

Francisca - se tem muita entrega, a gente fica até a hora que precisa.

Cida - o cliente não manda aqui. Eu dito as regras. Eu quem digo o dia da entrega. Na empresa a pessoa diz que você tem que fazer isso. Nós aqui não temos de fazer nada. Nós fazemos porque temos responsabilidade.

\section{Silêncio e submissão}

Essa situação refere-se à própria situação colonial. Diferencia-se do consentimento não por reforçar o discurso, mas, sim, pela falta de voz dos sujeitos submissos. Entendemos que os discursos aqui expostos 
retratam a subalternidade presente nas relações entre mulheres; passadeiras e lavadeiras; mulheres e clientes; e mulheres e governo.

Cida explicou a dinâmica do trabalho da "parte de baixo", como é chamado o recinto onde ficam as lavadeiras.

Cida - nós trabalhamos em par. Cada passadeira tem uma lavadeira. Quando tem uma vaga lá em cima (passadeira)...

(perguntamos se alguém quer subir)

Cida - quase nunca querem (sorri).

Cida - se eu pego a roupa pra passar e está mal lavada, eu devolvo para ser lavada de novo, quantas vezes for preciso.

O recinto de lavação de roupas é dividido ao meio e comporta doze posições, ou seja, em cada lado da divisão, há seis tanques de alvenaria, com batedor, dispostos lado a lado, lembrando os sweatshops. Em frente aos tanques, observamos algumas pedras de sabão grudadas na parede. Elas colocam oito pares de barras de sabão nesta parede de modo que formem um quadro de um tamanho suficiente para passar a escova e levá-la, já com sabão, até a roupa e esfregá-la. Perguntamos a uma delas quem fez aquilo. A resposta foi: "Nós inventamos. É mais fácil desse jeito. A gente não perde tempo, o movimento já vai direto".

Elas passam as roupas e as colocam dobradas à sua frente. Observamos na pilha de roupas dobradas dos clientes a existência de roupas íntimas. Apesar de em outros momentos as permissionárias proclamarem a autonomia, em outros momentos fica patente que o lugar da fala não lhes pertence, pois se silenciam diante das ordens dos clientes.

Edilene - eles trazem de tudo. Roupa íntima, roupa de cachorro, tapete.

Cida - da roupa íntima não, mas dos outros cobramos preço diferenciado.

Edilene - nós não falamos nada. Apenas cobramos.

Cida - passar é arte. Não é só pegar e passar. O cliente chega aqui com a medida do vinco, fala do jeito que quer, se é beirada para fora, com vinco, sem vinco, cada um quer de um jeito. Nós não escrevemos isso não, a gente acostuma-se com a prática.

O processo de atribuir ao outro a inferioridade, com o objetivo de desempenhar o papel de sujeito, está presente na conversa a seguir, quando elas se referem ao tratamento que a população carente recebe do governo.

Francisca - a minha mãe ficou com AIDS (Síndrome da Imunodeficiência Adquirida) quinze dias. Exame trocado. Ela ficou quinze dias chorando, sem contar nada pra ninguém, sofrendo calada. Até que o outro exame que ela fez deu negativo.

Cida - o descaso é muito com a população.

Depois de uma pausa, Cida revela a necessidade de representação junto ao órgão do governo quando diz: "Nós já pedimos na prefeitura um auxílio pra pagar a água. O que ouvimos foi: 'Cês (sic) não são uma empresa? A empresa tem que pagar as despesas'. Aí desistimos". O fato de desistirem de pleitear um 
donativo ou desconto junto ao órgão municipal é a admissão de que precisam de representação e de que não há possibilidade de luta, pois o sujeito subalterno não pode se fazer ouvir.

O fragmento de uma conversa a seguir evidencia a relação de subalternidade entre as lavadeiras e passadeiras. Ao dizer "aqui em cima" e "aqui em baixo", Edilene qualifica e divide as permissionárias em dois grupos. Continuando, Cida reforça a importância do trabalho das passadeiras e confirma o silêncio a que estão sujeitas as lavadeiras que ficam na parte de baixo, caracterizando a figura do subalterno (SPIVAK, 1988).

Cida - acho que vou lá pra baixo, voltar a lavar.

Edilene - não deixo de jeito nenhum.

Cida - eu já falei isso e as meninas não deixam (sorri).

Cida - o trabalho mais difícil é o de passar. Aqui em cima (referindo-se ao local em que as passadeiras trabalham) é que os clientes vêm, entregam a roupa, conversam. Lá em baixo, elas só lavam a roupa, não têm que atender o cliente. A pressão aqui é muito grande. Contato com o cliente. Dar satisfação para o cliente... quem lava faz o trabalho mais tranquilo, é só fazer o que tem que ser feito. Não fala nada. Não tem que dizer nada. Lavar roupa, num instantinho lavo um montão.

(perguntamos a Cida se ser lavadeira ou passadeira é uma opção das mulheres)

Cida - a opção de lavar ou passar é da pessoa. E onde tem vaga. Agora entrou uma que aprende a lavar e passar. Quando tiver que arrumar uma pra ajudar, ela escolhe. A outra tem que se adequar. Se surge uma vaga pra passar, a gente pergunta se alguém quer subir. Normalmente ninguém quer. Os pares são formados pela ordem em que chegam.

As relações de poder são desiguais. O colonizador, um sujeito hegemônico, não considera relações simétricas, pois marginaliza o outro. As mulheres sofrem os efeitos da colonização e do patriarcalismo, sendo relegadas duplamente a uma condição inferior (SPIVAK, 1988). Isso pode ser observado na conversa a seguir, na qual a mulher é retratada como objeto sexual pelos homens e, ainda, uma ameaça à vida conjugal, pelas outras mulheres.

Cida - tem muito cliente que passa umas cantadas. Fazem umas piadinhas, e se a gente abre a guarda... E as mulheres entram na cola do cliente e fica olhando. Uma vez o cliente cismou com uma moça aqui. Negra, muito linda, casada. Ele não queria nem saber, quis sair com ela de todo jeito. Uma vez a mulher perguntou: "Ah, é você que cuida da nossa roupa?" Na vez seguinte ela chegou e falou: "Posso trocar de lavadeira?" E pegou uma senhora.

Edilene - o problema é das mulheres que acham que as mulheres aqui são feias e desarrumadas. Aqui a gente atende clientes, então ficamos bem arrumadas. Aí as mulheres falam: "não pensei que fosse assim".

Cida - outra cliente disse: "Quando meu noivo vier aqui vocês vão ver o hômi mais lindo do mundo. Não fiquem olhando pra ele não".

Edilene - e eu vi quando a mulher falou: "Aquela loirinha lá do fundo tem cara de perigosa" (referindo-se a Edilene). 
Cida - a gente vê que elas tão (sic) com ciúme. A gente vê, percebe, mas não dá moral.

A submissão nem sempre é explícita. Cida estabeleceu uma ordem de não trabalhar aos sábados por influência de sua religião. A escolha de não trabalhar não é de nenhuma delas, pois estão submissas à imposição religiosa de Cida.

Cida - nós escolhemos quando trabalhar.

Edilene - a Cida não deixa a gente trabalhar no sábado, mesmo se quiser.

Cida - é uma regra não trabalhar no sábado. Se deixar uma trabalhar, quebra as regras.

Além das falas de Cida e dos outros atores, durante o período de shadowing fizemos algumas observações. As permissionárias trabalham em pé o tempo todo, de forma ininterrupta, maltratando o próprio corpo. As tarefas a que estão sujeitas são repetitivas e elas as realizam sem pausas que possam prevenir doenças ocasionadas pelo trabalho. Entendemos esse fato como uma tentativa de resistência, pois é a forma encontrada para não se submeterem a um só "patrão". Contudo, mesmo nesse lugar, não é possível sair dos meandros da força do discurso colonial.

Ao longo do dia, as lavadeiras procuram Cida para pedir uma orientação, uma licença ou material. As passadeiras a procuram para fazer os registros e anotações do trabalho executado. Durante todo tempo, uma das permissionárias, Maria do Carmo, idade de 69 anos, não disse uma palavra; séria e compenetrada no trabalho, sua voz não se fez ouvir nenhuma vez. Interpretamos que a lavanderia não é o "lugar da fala" (PRASAD, 2003) para Maria do Carmo e, possivelmente, para outras permissionárias.

Os clientes do sexo masculino pegam a roupa passada e levam para o carro. Já as clientes mulheres esperam que as passadeiras levem a roupa passada no carro, o que é feito. Essa é uma típica relação de submissão entre mulheres e mulher, e reforça o que Spivak (1988) afirma sobre a falta de solidariedade entre os distintos grupos subalternos. Cida não se veste diferente das demais. Não supervisiona o trabalho das outras permissionárias. Porém, é ela quem gerencia as contas, toma as decisões mais amplas da lavanderia, e é respeitada por todas. Cida, casada, negra, evangélica, um gênero construído como o outro, revela, dentro da lavanderia, esse outro, e às vezes, revela-se como o Outro.

\section{Considerações Finais}

Considerando as questões principais discutidas no pensamento pós-colonial, nossa análise revelou-se apropriada para revelar as configurações de gênero no local pesquisado. Ao identificar as três configurações das relações de gênero, a resistência, o consentimento, e o silêncio e submissão, o estudo revelou como os sujeitos pesquisados ora se revestem de uma configuração, ora de outra, transitando entre diferentes categorias identitárias.

A criação de estereótipos é um instrumento eficiente para assegurar a dominação, pois o colonizador constrói o "outro" pela ideia das diferenças de raça ou classe de indivíduos mais aptos e melhores que outros. O esforço da crítica pós-colonial se concentra em encontrar o lugar da fala para que o sujeito subalterno não se faça representar. Ao fazer isso, os teóricos pós-coloniais buscam as brechas no discurso dominante, no discurso do colonialismo e do patriarcalismo. Neste caso, consideramos que a lavanderia não se constitui o lugar de fala para as mulheres, ainda que tenha uma natureza comunitária e que o trabalho seja executado apenas por mulheres. 
O pensamento pós-colonial amplia o foco dos estudos de gênero nas organizações, visto que discute questões fundamentais para o entendimento do sujeito pós-colonial feminino, um sujeito que é constituído como o "outro". O conhecimento produzido no centro não é suficiente para interpretar o que acontece em outros lugares; portanto, é necessário refletir sobre o que se produz no centro e na periferia e como esse conhecimento explica diferentes culturas.

Este estudo contribui para o campo dos Estudos Organizacionais ao ilustrar como a análise pós-colonial descortina o modo como os sujeitos pós-coloniais ora reforçam o discurso ocidental, ora o negam. Outra contribuição refere-se à aplicação da técnica shadowing, ou acompanhamento, nos estudos organizacionais brasileiros. A técnica, até então empregada no estudo de comportamento de gerentes, mostrou-se adequada para revelar as práticas discursivas em relação a gênero e ao poder. Ressaltamos, ainda, o caráter de originalidade e ineditismo deste artigo, haja vista a ausência de estudos, no Brasil, que focalizem gênero na perspectiva pós-colonial e, ainda, pela utilização da técnica de pesquisa.

Apontamos, aqui, possíveis desdobramentos para o estudo de gênero no campo dos Estudos Organizacionais utilizando-se da perspectiva pós-colonial, sabendo que esse é um campo inesgotável. Como futuros desdobramentos desta pesquisa, sugerimos estudos que considerem outros espaços, como grandes empresas e corporações, brasileiras e multinacionais, para identificar os perfis das configurações inter e intragêneros. Sugerimos, ainda, que sejam analisados, na perspectiva pós-colonial, os discursos oficiais de empresas e da mídia voltada para negócios, no sentido de identificar o conceito de mulher.

\section{Referências}

ASHCROFT, B. Intersecting marginalities: post-colonialism and feminism. Kunapipi, v. 11, n. 2, p. 23-35, 1989.

CALÁS, M. B. Transnational/Postcolonial feminist theorizing. In: S. CLEGG; J. BAILEY (Eds.) International Encyclopedia of Organization Studies. London: Sage, 2007, p.1568-1571.

.; SMIRCICH, L. From "the woman's" point of view: feminist approaches to organization studies. In: S. CLEGG; C. HARDY; W. NORD. (Eds.). Handbook of organization studies. London: Sage, 1996, p. 218-257.

CALIXTO, F. de A. A geração de renda no Seringueiras (Uberlândia MG), a partir de trabalhadores de mão-deobra não qualificada e de baixa escolarização : uma leitura de justiça como equidade em processo político de intervenção no serviço social. 2001. 211f. Dissertação de Mestrado. Programa de Pós-Graduação em Serviço Social. Universidade Estadual Paulista, Franca, 2001.

CAPPELLE, M. et al. A produção científica sobre gênero na Administração: uma meta-análise. In: ENCONTRO DA ASSOCIAÇÃO NACIONAL DE PÓS-GRADUAÇÃO EM ADMINISTRAÇÃO, Salvador, 30., 2006, Salvador. Anais... Salvador, BA, 2006.

CARNEIRO, S. Mulheres em movimento. Estudos Avançados, v. 17, n. 49, p. 117-132, 2003.

CHANDA, I. Feminist theory in perspective. In: H. SCHWARZ; S. RAY (Eds.) A Companion to Postcolonial Studies. Oxford: Blackwell Publishing, 2005, p.486-507.

CORRÊA, A; CARRIÉRI, A. Percurso semântico do assédio moral na trajetória profissional de mulheres gerentes. Revista de Administração de Empresas, v. 47, n. 1, p. 22-32, 2007.

COSTA, C. O leito de procusto: gênero, linguagem e as teorias femininas. Cadernos Pagu, n. 2, p. 141-174, 1994.

CZARNIAWSKA, B. Shadowing: and other techniques for doing fieldwork in modern societies. Copenhagen: Business School Press, 2007.

D’ÁVILA NETO, M. O autoritarismo e a mulher: o jogo da dominação macho-fêmea no Brasil. Rio de Janeiro: Achiamé, 1980. 
ESTEVES, P. Cordialidade e familismo amoral: os dilemas da modernização. Revista Brasileira de Ciências Sociais, v. 13, n. 36, p. 109-120, 1998.

FONSECA, C. Prefácio. In: M. PEDRO; M. GROSSI (Orgs.). Masculino, feminino, plural: gênero na interdisciplinaridade. Florianópolis: Ed. Mulheres, 1998.

FOUCAULT, M. L’Archéologie du savoir. Paris: Gallimard, 1969.

FREYRE, G. Casa Grande \& Senzala. 27. ed. São Paulo: Brasiliense, 1988.

GRZYBOVSKI, D.; BOSCARIN, R.; MIGOTT, A. Estilo feminino de gestão em empresas familiares gaúchas. Revista de Administração Contemporânea, v. 6, n. 2, p. 185-207, 2002.

HALL, S. The West and the Rest. Discourse and Power. In: HALL, S. et al. (Eds.) Modernity: introduction to the modern societies. Oxford: Blackwell, 1996, p.185-227.

MCDONALD, S. Studying actions in context: a qualitative shadowing method for organizational research. Qualitative Research, v. 5, n. 4, p. 455-473, 2005.

MELO, M. C. et al. Representações femininas na mídia de negócios brasileira. Organização \& Sociedade, v. 11, n. 31, p. 103-118, 2004.

MINTZBERG, H. The nature of managerial work. New York: Harper \& Row, 1973.

MOHANTY, C. Under western eyes: feminist scholarship and colonial discourse. Boundary, v. 12, n. 3, p. 333-358, 1984.

PEREIRA, A. N; MACHADO, V.; VILAS BOAS, A. A inserção feminina no mercado de trabalho do agronegócio: um estudo comparativo da Sadia e da Perdigão. Organizações Rurais \& Agroindustriais, Lavras, v. 10, n. 1, p. 23-34, 2008 .

PERROT, M. Os excluídos da história: operários, mulheres e prisioneiros. Rio de Janeiro: Paz e Terra, 1988.

. História das mulheres no Ocidente. Porto: Afrontamento, 1990.

PICKERING, A. From science as knowledge to science as practice. In: A. PICKERING. (Ed.). Science as practice and culture. Chicago: University of Chicago, 1992, p. 1-26.

PRASAD, A. Postcolonial theory and organizational analysis: a critical engagement. Palgrave: McMillan, 2003.

QUINLAN, E. Conspicuous invisibility: shadowing as a data collection strategy. Qualitative Inquiry, v. 14, n. 8, p. 1480-1499, 2008.

SANTOS, H. A busca de um caminho para o Brasil: a trilha do circulo vicioso. São Paulo: Editora Senac, 2001.

SCOTT, J. Gênero: uma categoria útil de análise histórica. Educação \& Realidade, v. 20, n. 2, p. 5-22, 1988.

SPIVAK, G. Can the subaltern speak? In: C. NELSON; L. GROSSBERG. (Eds.) Marxism and the Interpretation of Culture. Illinois: University Press, 198, p. 66-111.

STEIL, A. Organizações, gênero e posição hierárquica: compreendendo o fenômeno do teto de vidro. Revista de Administração, v. 32, n. 3, p. 62-69, 1997.

SULERI, S. Woman skin deep: feminism and the postcolonial condition. Critical Inquiry, v. 18, n. 1, p. 756-769, 1992.

VAITSMAN, J. Gênero, identidade, casamento e família na sociedade contemporânea. In: R. MURARO. (Org.). Mulher, gênero e sociedade. Rio de Janeiro: Relume Dumará, 2001, p.5-20. 